\title{
"Do Brasil Colônia de Ontem ao Brasil Nação de Amanhã". "Revolução da Independência" e História do Brasil em Caio Prado Jr.*
}

\author{
Bernardo Ferreira
}

$\mathrm{E}$ m prefácio à primeira edição de Evolução Política do Brasil ${ }^{1}$, seu livro de estréia como historiador, em 1933, Caio Prado Jr. procura justificar os motivos de sua opção por escrever um "simples ensaio" em lugar de uma "história completa" (EPB:7). Uma das razões, segundo o autor, estaria no fato de que a elaboração de uma "história completa" exigiria a reunião de informações ainda não disponíveis, já que os historiadores tenderiam a se dedicar exclusivamente à "superfície dos acontecimentos" (EPB:7), ignorando "o que se passa no íntimo da nossa história de que estes acontecimentos não são senão um reflexo exterior" (EPB:8). Uma abordagem que voltasse sua atenção para esse "íntimo da nossa história" era o que pretendia aquele "simples ensaio" e, para tanto, informa-nos, recorria a "um método relativamente novo", à "interpretação materialista" (EPB:7). Enfim, o que o leitor tinha em mãos era um "ensaio de interpretação materialista da história brasileira"2.

No entanto, para além de uma rápida observação sobre a necessidade de ir além de uma história das classes dirigentes (EPB:8), Caio Prado Jr.

\footnotetext{
* Este artigo foi originalmente escrito em 1990 como relatório final de uma bolsa de iniciação científica. A versão que ora se apresenta suprime uma parte intermediária em que se discutia o pensamento de Marx e preserva, com algumas modificações na forma, a análise sobre a obra de Caio Prado Jr. A pesquisa que deu origem ao texto foi feita sob a orientação da professora Berenice Cavalcante. Por sua importância na realização deste estudo e, sobretudo, em minha trajetória de estudante universitário, gostaria de dedicar o artigo a ela.
}

DADOS - Revista de Ciências Sociais, Rio de Janeiro, Vol. 51, n²2, 2008, pp. 489 a 509. 


\section{Bernardo Ferreira}

não oferece uma indicação mais precisa sobre o que seria a "relativa novidade" do método empregado em Evolução Política do Brasil. $\mathrm{Na}$ verdade, seja nesse livro, seja em suas obras posteriores sobre a história brasileira - Formação do Brasil Contemporâneo: Colônia (1942) e História Econômica do Brasil (1945), não encontramos muitos elementos para responder a essa indagação. Discretos quanto aos problemas de fundo teórico ou metodológico, esses textos privilegiam a análise documental e as referências de cunho historiográfico, e apresentam um uso relativamente restrito do aparato conceitual do marxismo ${ }^{3}$.

Isso não significa, naturalmente, que a "interpretação materialista" prometida em 1933 tenha ficado no mero anúncio. Uma leitura atenta de suas obras históricas poderia revelar-nos alguns dos elementos que organizam essa interpretação. Para efeito de exposição, recupero algumas formulações contidas em A Revolução Brasileira que permitam expor, de maneira até certo ponto esquemática, traços gerais dessa "interpretação materialista", tal como se apresenta nos principais textos históricos de Caio Prado Jr. Adianto, desde já, que, ao discutir a natureza da interpretação materialista da história em Caio Prado Jr., não estou preocupado em avaliar a correção de sua abordagem ou a especificidade de sua apropriação do marxismo para pensar a realidade do Brasil ${ }^{4}$. O objetivo deste artigo é ao mesmo tempo mais modesto e diferente: tenho em vista prioritariamente a imagem da história brasileira que se elabora em seus textos. Pretendo sublinhar alguns dos elementos que estruturam sua análise sobre a formação histórica do país, articulando-os a seu diálogo com o pensamento marxista. Desse modo, insisto, A Revolução Brasileira oferece algumas fórmulas sintéticas e convenientes que, em seu relativo esquematismo, podem servir como ponto de partida para a discussão do meu problema ${ }^{5}$.

São três os pontos que gostaria de destacar. Comecemos por uma observação de Caio Prado Jr. sobre o que seria a novidade do "método dialético":

o que precisamente o marxismo, com seu método dialético, introduziu de novo na análise e interpretação históricas [...] é a explicação dos fatos e das situações históricas pela emergência progressiva deles dentro de um processo em permanente devenir, e se projetando assim para o futuro numa perpétua renovação. Isto é, sem repetir o passado, ou melhor, sem se modelar segundo formas e circunstâncias pré-fixadas $(R B: 34$, ênfase no original). 
É preciso não esquecer o contexto da polêmica em que essa observação está inserida: a abordagem de Caio Prado Jr. sobre a novidade da interpretação marxista da história tem como alvo o determinismo que, a seu ver, orientava a interpretação do Partido Comunista Brasileiro - PCB sobre a história brasileira. Para o autor, esta última deveria ser abordada a partir de sua especificidade, evitando reduzir as trajetórias das diferentes sociedades a um esquema predefinido e universalizável. Seria, portanto, necessário considerar a história de cada sociedade a partir das circunstâncias particulares que presidiram sua formação e que permitiriam analisar o presente como parte de um processo que remonta ao passado e se projeta no futuro. No entanto, interessa-me menos destacar as importantes divergências entre Caio Prado Jr. e seus adversários do que o solo comum a ambos. A polêmica que sustenta em A Revolução Brasileira parte de uma premissa que, no final das contas, é partilhada pelos dois lados: a concepção de que o acontecer histórico possui a natureza de um processo. Sua crítica se dirige à forma como esse processo é concebido, mas não à própria idéia de processo. $\mathrm{Ou}$ seja, põe em questão o ponto de vista apriorístico, abstrato - uma "teorização às avessas que vai dos conceitos aos fatos, e não inversamente desses fatos aos conceitos" (RB:29) -, mas continua a pressupor que os eventos individuais só podem ser compreendidos como parte de um acontecer global, no qual eles ganham sua razão de ser. Nas palavras do próprio autor, "considerados dialeticamente, os fatos sociais somente têm significação como componentes de processo; e assim, como resultantes de um passado onde se elaboram suas premissas, e como elementos dinâmicos que se projetam para o futuro" (RB:81, ênfase no original).

Se os trechos citados são expressivos da filiação de Caio Prado Jr. à noção de história como processo, são ainda muito pouco esclarecedores de seu entendimento do "método dialético". A noção de processo histórico não é exclusiva da tradição marxista, muito menos encontrou nela sua primeira formulação, mas, como assinala Hannah Arendt (1979), é própria do conceito moderno de história ${ }^{6}$. Cabe, por isso, uma pergunta: como Caio Prado Jr. caracteriza a natureza do processo histórico? Nesse ponto, um novo trecho de A Revolução Brasileira pode nos ajudar:

[as] contradições através de que se desenrola o processo histórico-social [...] se caracterizam pela eclosão, no interior de qualquer situação, e em função dela mesmo e como seu contrário, de uma situação 


\section{Bernardo Ferreira}

distinta que tende a eliminá-la. É na superação dessas contradições, isto é, pela eliminação dos contrários e conflitantes que nelas ocorrem, e sua síntese, que reside o dinamismo dos processos histórico-sociais, e que se situam as forças internas que impelem o curso dos acontecimentos que fazem a trama da história" (RB:134).

Se nos trechos inicialmente citados o conceito de história era identificado à noção de processo, agora é a natureza mesma desse processo que está em jogo. Não é difícil reconhecer aqui as linhas gerais da concepção de Hegel, reapropriada por Marx, da progressão dialética da história. O "dinamismo dos processos histórico-sociais" é impulsionado por contradições surgidas no seio de uma determinada conjuntura. Da solução de tais contradições, de "sua síntese", nutrir-se-ia o movimento histórico. Dessa forma, a compreensão dos fatos sociais implicaria não apenas sua inserção no interior de um processo mas também o reconhecimento da estrutura contraditória do acontecer, a afirmação do "caráter negativo da realidade" (Marcuse, 1978:285). É pela negação da negação que a história avança.

Contudo, se me limitasse a esses dois pontos, estaria ignorando um dos ingredientes centrais da novidade que Caio Prado Jr., em 1933, reivindicava para sua interpretação da história brasileira: seu caráter materialista. É preciso, portanto, acrescentar mais um elemento: a afirmação de que o fundamento material do desenrolar do processo histórico se encontra na esfera da vida econômica. Ali estariam bases do movimento contraditório da história. Dessa forma, a economia se torna, em Caio Prado Jr., assim como em Marx, o ponto de partida para a análise da história. É preciso partir da organização econômica para, em seguida, compreender o conjunto da organização social que tem nela seu fundamento. Como observa o historiador, "a estrutura de classe de uma sociedade e a natureza e a hierarquia de suas classes e categorias sociais refletem sempre a organização econômica que lhes serve de base" (RB:103). Uma leitura atenta de seus trabalhos históricos confirmaria essa perspectiva para outros aspectos da organização social.

Ao destacar esses três aspectos gerais da "interpretação materialista da história" proposta por Caio Prado Jr. - história como processo que se desenrola de forma contraditória e cujo fundamento se encontra na esfera da vida econômica -, minha pretensão não é, como disse antes, a exaustão. Os três pontos mencionados me interessam prioritariamente de um ponto de vista heurístico: podem servir de balizas para a discus- 
são sobre a imagem da história brasileira que Caio Prado Jr. apresenta em seus textos. Nesse sentido, acredito que sua análise sobre a "revolução da Independência" (EPB:9) oferece uma porta de entrada privilegiada para a abordagem dessa questão.

Com efeito, o episódio da Independência constitui, para o autor, "o primeiro grande acontecimento de conjunto" (FBC:357) de uma série de transformações desencadeadas pela "decomposição do sistema colonial" (FBC:357). Essa decomposição se manifesta sob a forma de um "mal-estar econômico e social" ( $F B C: 356)$, no qual um olhar atento poderia reconhecer retrospectivamente a "realidade que vai por baixo" (FBC:358), os "germes de autodestruição" (FBC:357) e as "forças renovadoras" ( $F B C: 357)$, que "indicam uma situação de conjunto nova" (FBC:357). Para Caio Prado Jr., a "origem de tais 'forças', que se manifestam exteriormente sobretudo por aquele mal-estar generalizado", deve ser buscada no "mais íntimo da sociedade colonial", em sua "infra-estrutura econômica" (FBC:358-359). Em resumo, com a Independência, vem "à tona dos acontecimentos" ( $F B C: 365)$ um processo mais amplo cuja compreensão exige ter em vista "as contradições profundas do sistema colonial, donde brotam os conflitos que agitam a sociedade, e donde brotará também a síntese que porá termo a tais conflitos, fazendo surgir um novo sistema em substituição ao anterior" (FBC:366).

Na Independência, portanto, o que se torna patente é a dinâmica da negação, graças à qual seria possível apreender "o fio condutor [...] na complexidade dos fatos" (FBC:358). Ainda assim, cabe perguntar: em que consiste esse processo de negação da ordem colonial de que a Independência seria apenas uma manifestação de superfície?

Estruturada como uma empresa mercantil destinada a fornecer produtos comercializáveis no mercado exterior, a colonização, segundo Caio Prado Jr., é antes de tudo um "negócio" (FBC:32). Trata-se de "um capítulo da história do comércio europeu" (FBC:22), um desdobramento da expansão marítima e mercantil européia do fim do século XV. Ocupação e povoamento dos trópicos foram o resultado da tentativa de tornar as terras descobertas interessantes do ponto de vista comercial. Voltada para fora, a exploração econômica das possessões ibéricas no Novo Mundo vai se estruturar com o objetivo de produzir gêneros tropicais ou minerais de grande aceitação no comércio exterior. Tal é o "sentido da colonização" (FBC, cap. 1), e é ele que vai explicar as bases sobre as quais se organiza a economia da colônia. Esta gira em torno da 


\section{Bernardo Ferreira}

"grande unidade produtora, seja agrícola, mineradora ou extrativa" (FBC:124), a qual alia uma estrutura específica de propriedade a um sistema de organização e exploração de mão-de-obra. A terra será explorada no regime de grande propriedade, em que uma ampla faixa de terra estará a serviço do aproveitamento extensivo de suas potencialidades econômicas. Na agricultura, o resultado será o latifúndio agroexportador baseado na monocultura. Quanto ao sistema de exploração de mão-de-obra, o trabalho na colônia será essencialmente escravo, congregando um grande número de indivíduos sob o controle de um empresário. Daí resultará o caráter fortemente concentrador desse sistema econômico. Podem-se observar variações aqui e acolá, mas em sua essência o quadro sempre será o mesmo:

de um lado, na sua estrutura, um organismo meramente produtor, e constituído só para isto: um pequeno número de empresários e dirigentes que senhoreiam tudo, e a grande massa da população que lhe serve de mão-de-obra. Doutro lado, no funcionamento, um fornecedor do comércio internacional dos gêneros que este reclama e de que ela dispõe. Finalmente, na sua evolução, e como conseqüência daquelas feições, a exploração extensiva e simplesmente especuladora, instável no tempo e no espaço, dos recursos naturais do país (FBC:129, ênfases no original).

Como resultado, temos uma organização econômica que "não constitui a infra-estrutura própria de uma população que nela se apóia, e destinada a mantê-la" (FBC:128). Em lugar disso, essa população se torna apenas "o elemento propulsor" (FBC:128) de um "mecanismo" (FBC:128) cujas finalidades lhe são estranhas. Fundada na grande unidade produtora, baseada na exploração de mão-de-obra escrava e voltada para a produção de gêneros comercializáveis no mercado exterior, a economia colonial, segundo Caio Prado Jr., não foi capaz de dar origem a uma estrutura social complexa e integrada. Pelo contrário, "a sociedade colonial se definirá antes pela desagregação, pelas forças dispersivas" (FBC:345). Dessa forma, na análise de Caio Prado Jr., a estrutura da ordem social da colônia apresentar-se-á cindida em dois núcleos, correspondentes, em sua essência, aos dois setores que compõem a economia. De um lado, o núcleo organizado da sociedade; de outro, o núcleo inorgânico. Este é o resultado do setor de subsistência da economia, voltado para o mercado interno; aquele deriva do setor principal da economia, o de exportação, no qual predomina o trabalho escravo $^{7}$. A feição da sociedade colonial será profundamente marcada por essa dualidade. Nos pólos extremos, estão os grupos sociais que se 
originam do setor organizado da economia: senhores e escravos. Seu vínculo é com a atividade produtiva voltada para o mercado externo: "Entre estas duas categorias nitidamente definidas e entrosadas na obra da colonização comprime-se o número, que vai avultando com o tempo, dos desclassificados, dos inúteis, dos inadaptados" (FBC:281). Esse grupo, estabelecido à margem do aparelho produtivo direcionado para a exportação, constitui, aos olhos de Caio Prado Jr., "o fator da futura nacionalidade" (Dias, 1989:385). Sua característica fundamental, no entanto, é - como o trecho citado anteriormente deixa entrever a desestruturação. Caio Prado Jr. multiplica as expressões que buscam sublinhar o caráter problemático desse setor da sociedade: inutilidade, embrutecimento, degradação, desocupação, instabilidade, marginalidade, desamparo, desenraizamento, incoerência. Seus componentes se tornam, no final das contas, "resíduos sociais inaproveitáveis" (FBC:285), que, simultaneamente, resultam do funcionamento do "mecanismo" da economia colonial e não se enquadram em suas engrenagens. Nas palavras do historiador,

em suma, a escravidão e as relações que dela derivam, se bem que cons-
tituam a base do único setor organizado da sociedade colonial [...], não
frutificam numa superestrutura ampla e complexa. Serviram apenas
para momentaneamente conservar o nexo social na colônia. No outro
setor dela, o que se mantém à margem da escravidão, a situação se apre-
senta em certo sentido pior. A inorganização é aí a regra [...].
É isto, em resumo, que o observador encontrará de essencial na socie-
dade da colônia: de um lado uma organização estéril no que diz respei-
to às relações sociais de nível superior; doutro, um estado, ou antes um
processo de desagregação mais ou menos adiantado, conforme o caso,
resultante ou reflexo do primeiro, e que se alastra progressivamente.
(FBC:344).

Como o próprio Caio Prado Jr. faz questão de observar, o quadro que nos apresenta do sistema colonial não se restringe a uma descrição dos mecanismos políticos e administrativos que constituem o regime de subordinação da colônia em face da metrópole. Para o autor, a idéia de sistema colonial teria um conteúdo mais amplo, consistindo "no conjunto de caracteres e elementos econômicos, sociais e políticos que constituem a obra aqui realizada: pela colonização" (FBC:358). Dessa forma, integrada no conjunto do sistema colonial, a sociedade colonial não pode ser completamente distinguida dele: à base econômica fundada na grande unidade produtora voltada para exportação corres- 


\section{Bernardo Ferreira}

ponde uma ordem social precária e desconexa, em uma "ausência quase completa de superestrutura" (FBC:342). Como vimos, é justamente na crise do sistema colonial que Caio Prado Jr. localiza as "raízes profundas" (FBC:356) do processo de independência. No final do século XVIII, a progressiva desagregação desse sistema e as contradições daí resultantes são o resultado do esgotamento das estruturas que haviam sido geradas pelo processo de colonização. As contradições surgem do fato de que essas estruturas, que se haviam constituído para a exploração econômica do Novo Mundo, agora se revelavam insuficientes para dar conta de novas necessidades que o próprio desenrolar da atividade colonizadora produzira:

[...] o sistema de colonização adotado no Brasil, o nosso "sistema colonial", depois de ter produzido durante três séculos frutos apreciáveis que contrabalançavam o negativo da sua feição, tocara o extremo da sua evolução, pelo menos em alguns e principais de seus aspetos, e a curva que desenhara na História começava a infletir decididamente para baixo, para sua consumação. Esgotara as suas possibilidades, e seria necessariamente substituído por outro ( $F B C: 360)$.

Podemos dar um passo adiante. A decomposição do sistema colonial de que falava há pouco - é, diz-nos Caio Prado Jr., o resultado do esgotamento de suas possibilidades históricas. As razões dessa exaustão já sabemos: devem ser buscadas na base econômica da sociedade. Em Evolução Política do Brasil, o historiador interpretava esse processo de desgaste como fruto de uma inadequação entre infra e superestrutura, como o resultado da contradição crescente entre o desenvolvimento econômico alcançado pela colônia e a preservação de sua subordinação à metrópole. A partir da segunda metade do século XVII, interesses coloniais e metropolitanos, que inicialmente concordavam entre si, começam a se diferenciar de forma cada vez mais explícita: "Revela-se então a contradição fundamental que minava o regime: interesses nacionais e portugueses díspares" (EPB:33). Segundo Caio Prado Jr., os principais grupos portadores desses interesses contrapostos são, por um lado, os proprietários rurais brasileiros, por outro, os comerciantes portugueses. Não creio ser preciso me prolongar sobre esse ponto detalhando a natureza desses conflitos e de seus desdobramentos. Basta-me assinalar que, nesse caso, a estrutura conceitual de sua análise corresponde, em linhas gerais, ao esquema que Marx apresenta no prefácio ao livro Para a Crítica da Economia Política, no qual aborda o problema da mudança social e da revolução. Trata-se, para Caio Prado Jr., 
de um processo desencadeado pelo desenvolvimento das forças produtivas e por seu choque com as estruturas políticas da ordem colonial. Em 1933, sua interpretação da "revolução da Independência" insiste na idéia de que

a emancipação política do Brasil resultou do desenvolvimento econômico do país, incompatível com o regime de colônia que o peava, e que por conseguinte, sob sua pressão, tinha de ceder. Em outras palavras, é a superestrutura política do Brasil-Colônia que, já não correspondendo ao estado das forças produtivas e à infra-estrutura econômica do país, se rompe para dar lugar a outras formas mais adequadas às novas condições econômicas e capazes de conter a sua evolução $(E P B: 52)^{8}$.

Ainda que em Formação do Brasil Contemporâneo Caio Prado Jr. faça referência à análise desenvolvida em Evolução Politica do Brasil sobre as oposições entre comerciantes e proprietários, o pano de fundo de sua abordagem sobre esses conflitos sofre uma sensível alteração ${ }^{9}$. No último capítulo daquele livro, a crise do sistema colonial não se apresenta como resultado do desenvolvimento da base econômica da sociedade. Sua posição é bem mais complexa, e Caio Prado Jr. de certa maneira inverte o argumento. Em lugar de atribuir ao desenvolvimento das forças produtivas da colônia a causa das contradições que minam o sistema colonial, ele vai buscar a explicação nas insuficiências da economia colonial. Também aqui o segredo da desagregação do sistema colonial deve ser procurado na infra-estrutura. Só que, dessa vez, não mais em seu desenvolvimento, mas em suas limitações. A crise do sistema colonial tornaria evidentes os "vícios profundos e orgânicos" (FBC:356) de uma "economia constituída na base da exploração, e exploração precipitada e extensiva dos recursos naturais" (FBC:359). Segundo Caio Prado Jr.,

tal base com o desenvolvimento da população, com o concurso de outros fatores vários, se torna através do tempo, restrita e incapaz de sustentar a estrutura que sobre ela se formara. Suficiente no início, e ainda por muito tempo para prover aos fins precípuos da colonização - a ocupação do território, o aproveitamento dele com relativo equilíbrio econômico e social; para promover, enfim, o progresso das forças produtivas -, aquela base acabou por se tornar insuficiente para manter a estrutura social que sobre ela se constituíra e desenvolvera ( $F B C: 359)$.

Apesar da referência ao tema das forças produtivas nesse trecho, Caio Prado Jr., na seqüência de sua análise, não insiste, como era o caso em 


\section{Bernardo Ferreira}

Evolução Política do Brasil, na idéia de obstáculos à continuidade do desenvolvimento econômico impostos pela manutenção do regime de colônia. Basta considerar a oposição, que se mantém central no texto de 1942, entre comerciantes e proprietários rurais: aparece agora como fruto "das condições de uma economia débil, mal estruturada e conduzida, e visceralmente ligada a um mercado exterior precário e incerto" (FBC:366). Curiosamente, o esgotamento da economia colonial parece se resumir na radicalização daqueles "vícios profundos e orgânicos" do sistema de exploração econômica dominante, sem que o leitor consiga identificar as forças de negação que anunciariam uma futura síntese e a "situação de conjunto nova" de que nos fala o autor. No final do século XVIII, o quadro seria de quase "desagregação completa, se não paralisação da vida do país" (FBC:359). Os recursos necessários à manutenção da sociedade estariam se tornando cada vez mais limitados em virtude do "estado a que se reduzira o acervo material do território" (FBC:359). A natureza predatória da exploração dos recursos naturais teria "já quase esterilizado as fontes mais acessíveis de riqueza" (FBC:359). Ao mesmo tempo, dado fundamental, ao longo dos séculos teria ocorrido um aumento significativo da massa de desajustados e desclassificados, da massa livre da população que vivia à margem da ordem social e sem lugar no aparelho produtivo exportador. Segundo Caio Prado Jr., "enquanto houve apenas senhores e escravos, e é o que se dá no início da colonização, tudo ia bem" (FBC:360). No entanto, o crescimento numérico dessa "massa deslocada, indefinida, mal enquadrada na ordem social, e na realidade produto e vítima dela" (FBC:285) seria inevitável, agravando-se ainda mais no final do século XVIII, a ponto de se tornar "catastrófico" (FBC:286) ${ }^{10}$. Com isso, diz-nos o historiador, "o desequilíbrio era fatal" (FBC:360).

Como disse há pouco, inverte-se o argumento, já que é a base econômica do sistema colonial que constitui obstáculo à manutenção da ordem social montada sobre ela. Nesse caso, "o processo revolucionário que agitava a colônia" (FBC:368), embora se nutra de contradições que têm seu fundamento na infra-estrutura econômica, não resulta de seu progresso, mas de suas limitações. Resulta do "desequilíbrio fatal" decorrente de sua incapacidade de suportar uma estrutura social que ela mesma criara, mas cujo crescimento não tinha mais condições de manter. A crise do sistema colonial põe em evidência as insuficiências e os impasses de uma economia que, como vimos anteriormente, "não constitui a infra-estrutura própria de uma população que nela se apóia" (FBC:128). Uma economia que, orientada pelas oscilações do 
mercado externo, cada vez mais impotente para atender satisfatoriamente às necessidades internas que ela mesma originara, conduz a sociedade a um estado de "estagnação" (FBC:349).

Nesse ponto, chegamos a um problema central para a compreensão da "revolução da Independência" e, ao que me parece, da obra histórica de Caio Prado Jr. Surpreendentemente, o movimento que conduz à Independência não traz consigo uma transformação da infra-estrutura econômica do sistema colonial. Apesar disso, o historiador insiste na idéia de que o processo emancipatório assinala

uma nova fase bem caracterizada em nossa evolução econômica. Embora se conserve a estrutura anterior e fundamental que presidiu à formação e evolução colonial anterior (isto é, um organismo econômico primário, destinado a produzir alguns gêneros tropicais para o comércio internacional), entramos então nitidamente num período diferente do anterior (HEB:149-150).

Cabem algumas perguntas: em que consiste essa nova fase? Ela representa apenas uma ruptura com as estruturas jurídico-políticas do pacto colonial? Se for esse o caso, em que medida ainda se pode falar de uma "revolução da Independência"?

Talvez seja interessante voltar a discutir o capítulo "O Sentido da Colonização", que abre o livro Formação do Brasil Contemporâneo, para responder a essas questões. Esse texto lança as bases da interpretação da história brasileira feita por Caio Prado Jr., e não apenas o esquema de sua análise da sociedade colonial. Nesse sentido, é de importância central para se entender como Caio Prado Jr. aplica sua compreensão do "método dialético" à história nacional. Acredito que a partir dele seja possível pensar como se articulam os três eixos em função dos quais procurei esquematizar sua proposta de uma "interpretação materialista" da história.

O primeiro ponto a ser considerado é a própria noção de sentido que Caio Prado Jr. emprega. A idéia de sentido no texto pode, por um lado, ser vista como direção. Nesse caso, o sentido da colonização refere-se à orientação da empresa colonial, que, movida por interesses puramente mercantis, estabelece nos trópicos um "negócio" cujo objetivo é atender o comércio internacional. Como observa Caio Prado Jr., "é com tal objetivo exterior, voltado para fora do país e sem atenção a considerações 


\section{Bernardo Ferreira}

que não fossem o interesse daquele comércio, que se organizarão a sociedade e a economia brasileiras" (FBC:32, ênfases do autor).

Por outro lado, a noção de sentido comporta outra interpretação, permitindo a análise da história colonial como um processo dotado de significado. Ou seja, o sentido apresenta-se como uma totalidade significativa em que se insere o conjunto dos fatos que comporiam a história colonial. Isso porque

todo povo tem na sua evolução, vista à distância, um certo "sentido". Este se percebe não nos pormenores de sua história, mas no conjunto dos fatos e acontecimentos essenciais que a constituem num largo período de tempo. Quem observa aquele conjunto, desbastando-o do cipoal de incidentes secundários que o acompanham sempre e o fazem muitas vezes confuso e incompreensível, não deixará de perceber que ele se forma de uma linha mestra e ininterrupta de acontecimentos que se sucedem em ordem rigorosa, e dirigida sempre numa determinada orientação [...]. É isto que se deve, antes de mais nada, procurar quando se aborda a análise da história de um povo [...], porque todos os momentos e aspectos não são senão partes, por si só incompletas, de um todo que deve ser sempre o objetivo último do historiador (FBC:19).

Assim, a história da colônia apresenta-se como um processo cujo sentido (significado) está estreitamente vinculado ao sentido (direção) da empresa colonial. A colônia, portanto, é o resultado de um empreendimento mercantil voltado para o atendimento do mercado exterior. A noção de sentido em Caio Prado Jr. não constitui uma teleologia; não implica a idéia de um processo que caminha para um fim que está estabelecido desde o começo e que torna compreensível todo o seu desenrolar. O todo significativo que o sentido permite estabelecer não deriva de um fim presente já na origem, mas sim da concatenação de fatos e eventos históricos em um processo orientado do qual retiram seu significado. Eis por que tal sentido pode ser negado.

Como observa Caio Prado Jr., "não sofremos nenhuma descontinuidade no correr da história da colônia" (FBC:20). O sentido desta última permanece inalterado até o fim do século XVIII e início do século XIX, quando o sistema colonial começa a dar sinais de esgotamento. Abre-se, então, a possibilidade de negação do sentido; e é justamente a partir dessa idéia de negação do sentido da colonização - ou seja, a partir da negação da direção e do conseqüente significado assumidos pelo processo histórico da colonização - que Caio Prado Jr. vai conceber a história brasileira como um processo que se desenrola contraditoria- 
mente. Tal processo se desenvolve a partir de uma contradição fundamental que não teria sido resolvida até os dias atuais. Segundo o historiador, "este início, cujo caráter manter-se-á dominante através dos séculos da formação brasileira, gravar-se-á profunda e totalmente nas feições e na vida do país. Particularmente na sua estrutura econômica. E prolongar-se-á até nossos dias, em que apenas começamos a livrar-nos deste longo passado colonial" (HEB:22).

Sendo assim, as contradições que marcariam a história brasileira dispor-se-iam em círculos concêntricos em relação a uma contradição fundamental e de natureza originária: aquela que deriva do choque entre o sentido da colonização e sua negação. A negação da negação ainda estaria por ser concluída.

Tocamos, com isso, o terceiro ponto. A contradição básica subjacente ao processo através do qual a história brasileira vai se desenvolver a partir do século XIX tem seu fundamento na infra-estrutura econômica. O principal resultado da colonização - aquele que, como observado anteriormente, "gravar-se-á profunda e totalmente nas feições e na vida do país" - foi a constituição de uma economia colonial que se mantém, apesar das variações, como uma constante ao longo do tempo. Trata-se de "uma economia de exportação, constituída para o fim de fornecer gêneros alimentícios e matérias-primas tropicais aos países e populações das regiões temperadas da Europa e mais tarde também da América" (HEB:297). Nela se encontra a base material do sentido da história colonial, ao mesmo tempo que tem sua origem no sentido da colonização. Por oposição a essa economia colonial e como conseqüência de seu próprio desenvolvimento, a história brasileira registraria a formação gradual e acidentada de sua antípoda, a economia nacional. Esta significaria "a organização da produção em função das necessidades próprias da população que dela participa" (HEB:297). A primeira é direcionada para o mercado externo; a segunda, voltada para o mercado interno, representa o fundamento de uma nacionalidade orgânica e autônoma. O choque entre esses dois modelos de organização econômica constitui a contradição profunda, para usar um adjetivo caro a Caio Prado Jr., da qual deriva força interna ao processo histórico brasileiro. Segundo o autor, é "do jogo das contradições entre o passado colonial, que resiste, e as forças de renovação, que impulsionam o país por novos rumos, que resulta o processamento de nossa evolução econômica" (HEB:326).

As duas categorias - economia colonial e economia nacional -, espero que esteja claro, não possuem um caráter apenas descritivo. Cada uma 


\section{Bernardo Ferreira}

se define em contraposição à outra, e ambas oscilam entre os pontos de vista analítico e normativo ${ }^{11}$. Elas implicam não só um esforço de compreensão factual do curso da história brasileira mas também um posicionamento político em relação a esse acontecer. Na verdade, essa oscilação está diretamente associada ao fato de as duas noções darem voz a um problema central da reflexão de Caio Prado Jr. sobre o Brasil: o desencontro da sociedade brasileira consigo mesma, decorrente de seu passado colonial. Esse desencontro relegaria a maior parte da população do país a uma condição de mero instrumento ou, o que seria pior, de simples resíduo amorfo de uma ordem que lhe é estranha. A permanência do passado colonial com seu "sentido" implicaria uma espécie de alienação da sociedade em relação a seus destinos, a impotência política da grande massa da população e a manutenção de um estado de desarticulação interna da existência coletiva.

São essas mesmas questões que orientarão o corte temporal que Caio Prado Jr. estabelece na história brasileira dividindo-a em dois grandes períodos. Em Evolução Política do Brasil, esse corte parece ocorrer na segunda metade do século XVII. Já em Formação do Brasil Contemporâneo, o marco temporal está no fim do século XVIII e início do século XIX. No entanto, não são as diferenças que importam, mas sim o critério que preside a periodização em ambos os casos. Essa divisão da história brasileira define dois períodos qualitativamente diferentes. No primeiro, a história colonial propriamente dita, temos um corpo social precariamente constituído, carente de vida própria, "uma feitoria da Europa, um simples fornecedor de produtos tropicais para seu comércio" (FBC:127). Caio Prado Jr. aborda esse primeiro período de uma forma puramente descritiva das condições de vida existentes. Sua narrativa, de certo modo, congela o movimento dessa sociedade, não sendo assinalado qualquer evento que seja fruto do dinamismo interno da existência coletiva. Como observa Dias (1989:389), em Formação do Brasil Contemporâneo, essa narrativa é organizada segundo dois grandes eixos, no interior dos quais os diferentes capítulos do livro podem ser enquadrados. Em primeiro lugar, o "eixo da dependência colonial" (ibidem): somos apresentados às estruturas do sistema colonial e ao movimento de sua contínua reiteração que imobiliza o dinamismo da vida social. No segundo eixo, o da "formação da nacionalidade brasileira" (ibidem:390), observamos o desenvolvimento de possibilidades de organização da vida econômica e social que se desenvolvem à margem da ordem colonial dominante e como uma alternativa a ela. Embora esses dois eixos sejam pensados "em uma relação de permanente oposição estrutural" (ibidem:389), não parece resultar das formas de vida 
que descrevem nenhuma contradição verdadeiramente significativa. Isso porque tudo aquilo que se refere a um "caráter mais estável, permanente, orgânico, de uma sociedade própria e definida, só se revelará aos poucos, dominado e abafado que é pelo que o precede, e que continuará mantendo a primazia e ditando os traços essenciais da nossa evolução colonial" (FBC:31).

História quase sem contradições, que parece transcorrer no espaço, mas não no tempo, à qual corresponde, como disse, uma apresentação fundamentalmente descritiva e, por assim dizer, em paralelo das bases da ordem colonial e das formas de vida alternativas sufocadas por ela. $\mathrm{Ou}$, caso se prefira, história que parece ser presa de um tempo cíclico, em que a repetição do passado seqüestra as possibilidades de renovação do presente. Tal é o tempo da economia colonial, marcado por uma "evolução cíclica" (FBC:127), retornando obsessivamente, apesar das variações, ao mesmo roteiro de desenvolvimento. Essa evolução traz consigo "a repetição no tempo e no espaço de pequenas e curtas empresas de maior ou menor sucesso" (FBC:128); empresas que evoluem "por arrancos, em que se assiste ao progresso e ao aniquilamento de cada uma e de todas as áreas povoadas e exploradas do país" (FBC:128). O resultado final é sempre o mesmo: "farrapos de uma pequena parcela de humanidade em decomposição" (FBC:128). Isso porque se trata de uma ordem econômica que "não conta com forças próprias e existência autônoma" (FBC:128), desenvolvendo-se ao sabor das oscilações e dos humores da conjuntura que lhe é exterior. Para se libertar de seu próprio passado, para romper com a inércia de uma temporalidade da repetição, a sociedade brasileira teria de definir um centro próprio, que não estivesse a reboque de uma dinâmica externa.

O segundo período constitui o que se poderia chamar de história do Brasil contemporâneo. Nessa fase, o quadro se altera: "Aquilo que a colonização realizara, aquele 'organismo social completo e distinto' constituído no período anterior, começa a se transformar" (FBC, introdução:10). Com a crise do sistema colonial e o processo de independência, começa a se desdobrar uma realidade social dinâmica, marcada por um movimento próprio, e o processo histórico apresenta-se pontuado por eventos significativos. As tendências contraditórias do desenvolvimento histórico brasileiro, que permaneciam abafadas pelo "ambiente asfixiante" (FBC:285) gerado pelo predomínio inconteste do sentido da colonização, afloram "à tona dos acontecimentos". História repleta de contradições que resultam do choque entre um passado que teima em se manter vivo e um futuro por se concluir. Como palco desse 


\section{Bernardo Ferreira}

conflito, um presente em transformação, ainda impregnado de "passado, aquele passado colonial que [...] aí ainda está" (FBC, introdução:10-11), mas cheio de promessas de futuro. Assim, o Brasil contemporâneo apresenta-se como "um organismo em franca e ativa transformação e que não se sedimentou ainda em linhas definidas; que não 'tomou forma'" (FBC, introdução:11).

Nesse quadro, torna-se possível compreender o significado da "revolução da Independência". Ela se situa no interior do processo que marca a transição da história colonial para a história do Brasil contemporâneo e representa o "ponto de partida apenas, início de um longo processo histórico que se prolonga até os nossos dias e que ainda não está terminado" ( $F B C$, introdução:10). Fruto da própria desagregação do sistema colonial, o processo de emancipação coloca-se como marco de uma nova fase de nossa evolução econômica e social. A ruptura com a subordinação colonial e a formação de um Estado nacional independente trazem consigo a possibilidade de que a sociedade brasileira possa, daí em diante, estruturar-se segundo uma orientação própria; a possibilidade, enfim, do desenvolvimento de uma economia nacional. Este é o sentido da Independência como uma revolução: ainda que a partir dela não se observe uma transformação da base econômica herdada da colônia, ela está na origem da contradição fundamental que vai alimentar o dinamismo da história subseqüente. Nos termos do próprio Caio Prado Jr.:

É aliás na base das contradições geradas por aquela estrutura [a economia colonial] na nova situação e ordem para ela criados que evoluirão os acontecimentos. Existe um desacordo fundamental entre o sistema econômico legado pela colônia e as novas necessidades de uma nação livre e politicamente emancipada. Todos os desajustamentos que passamos em revista não são mais, em última instância, que reflexos e resultantes daquela contradição básica. Ela nos levará a uma evolução também contraditória (HEB:150).

Não é, portanto, uma transformação da economia que está na base da revolução, mas a revolução que está na origem de uma transformação da economia. Como resultado da Independência se abre a possibilidade de uma modificação da base econômica, que, em vez de se concretizar de imediato, se desdobra em um processo contraditório, ainda por concluir. A Independência não seria apenas a superação de um estatuto jurídico-político associado ao regime de colônia. Mais do que isso: significaria uma primeira ruptura com o sistema colonial, criando, desse modo, condições para a construção de uma nacionalidade orgâ- 
nica e autônoma por meio da reestruturação e reorientação da economia. Somente uma economia nacional permitiria erguer "a massa da população brasileira do simples estatuto de instrumento de trabalho e produção a serviço da imprensa mercantil aqui instalada pela colonização, para o plano de uma coletividade nacionalmente integrada e organizada" (RB:137).

Se entendemos a "revolução da Independência" fundamentalmente como um processo de transformação na infra-estrutura da sociedade colonial, em que a economia colonial começaria a ceder lugar a uma economia nacional, esse processo, no entender de Caio Prado Jr., permanece incompleto. Mais do que isso: confunde-se, em certa medida, com a própria história do Brasil contemporâneo. Esta se torna, portanto, uma revolução que transcorre a longo prazo, o que permitirá, mais tarde, a Caio Prado Jr. falar de quatro etapas principais: "a Independência política, a supressão do tráfico africano, e os dois corolários que daí derivam diretamente, a saber, a imigração de trabalhadores europeus a partir sobretudo do terceiro quartel do século passado, e a abolição do trabalho escravo" (RB:83).

Tornam-se mais claras, assim, as preocupações políticas que informam o trabalho intelectual de Caio Prado Jr. como historiador. Para ele, estudar a história brasileira significa compreender "o passado que nos fez" ( $F B C$, introdução:9) e cuja influência ainda nos assombra. Entender o Brasil contemporâneo é entender a sobrevivência de um passado que resiste à transformação. "Aquele passado que parece longínquo, mas que ainda nos cerca de todos os lados" (FBC, introdução:13) constitui um obstáculo à formação de uma nacionalidade integrada e organizada. A história do Brasil contemporâneo ainda não foi completamente contada, pois, sob muitos aspectos, "o 'sete-de-setembro' não tocou" (FBC:127). À política cabe a tarefa de promover a conclusão da Independência, exorcizando a história contemporânea de seu passado colonial. Para isso, é preciso compreender "melhor o processo que vai do Brasil colônia de ontem ao Brasil nação de amanhã, e que se trata hoje de levar a cabo. Tarefa essa que constitui precisamente a essência da revolução brasileira de nossos dias" (RB:83).

(Recebido para publicação em setembro de 2007)

(Versão definitiva em abril de 2008) 


\section{Bernardo Ferreira}

\section{NOTAS}

1. Legenda dos textos de Caio Prado Jr. citados: Evolução Política do Brasil - EPB; Formação do Brasil Contemporâneo: Colônia - FBC; História Econômica do Brasil -HEB e A Revolução Brasileira - RB.

2. Subtítulo da primeira edição do livro.

3. Como observa Carlos Nelson Coutinho, "o estoque de categorias marxistas de que se vale Caio Prado Jr. não é muito rico” (1989:116).

4. Creio que, de forma geral, essas questões encontram respostas satisfatórias no estudo de Ricupero (2000) sobre o processo de nacionalização do marxismo na obra de Caio Prado Jr.

5. Reconheço que o recurso a um livro escrito em 1966 - bem posterior, portanto, às três obras sobre a história brasileira escritas por Caio Prado Jr., que datam de 1933 (Evolução Política do Brasil), 1942 (Formação do Brasil Contemporâneo: Colônia) e 1945 (História Econômica do Brasil) -, em um contexto intelectual muito preciso - o da polêmica que mantém com os comunistas a respeito da interpretação da realidade social e da história brasileiras e das diretrizes para a ação político-revolucionária tiradas a partir daí -, pode se prestar a algumas objeções. Em particular, à objeção de que tal estratégia poderia levar a uma espécie de ilusão retrospectiva, resultante da projeção sobre aqueles textos de conclusões a que seu autor só teria chegado tardiamente. Parece-me, entretanto, que, no caso de A Revolução Brasileira, esse risco se encontra atenuado. Sempre que Caio Prado Jr. recorre a análises históricas nesse livro, não faz outra coisa senão reafirmar idéias já presentes em seus textos de história anteriores. Tal fato demonstra uma clara continuidade nas posições do autor com respeito à interpretação da história brasileira ao longo dos anos. Algo que pode ser, ademais, constatado pela reiteração de sua tese a respeito da natureza do desenvolvimento histórico brasileiro no post-scriptum de 1976 de História Econômica do Brasil. O mesmo vale para a estrutura e as premissas intelectuais básicas dessa interpretação. Daí que me parece legítimo sustentar não apenas uma continuidade mas também uma reafirmação, em A Revolução Brasileira, dos pontos de vista que orientaram as análises de Caio Prado Jr. em seus textos de história.

6. Ver também Koselleck (1985).

7. Sobre esse assunto, ver o excelente artigo de Dias (1989).

8. O texto de Marx é bem conhecido: "na produção social da própria vida, os homens contraem relações determinadas, necessárias e independentes da sua vontade, relações de produção estas que correspondem a uma etapa determinada de desenvolvimento de suas forças produtivas materiais. A totalidade destas relações de produção forma a estrutura econômica da sociedade, a base real sobre a qual se levanta uma superestrutura jurídica e política, e à qual correspondem formas sociais determinadas de consciência. O modo de produção da vida material condiciona o processo geral de vida social, política e espiritual. Não é a consciência dos homens que determina o seu ser, mas, ao contrário, é o seu ser que determina sua consciência. Em certa etapa do seu desenvolvimento, as forças produtivas materiais da sociedade entram em contradição com as relações de produção existentes ou, o que é nada mais do que a sua expressão jurídica, com as relações de propriedade dentro das quais aquelas até então se tinham movido. De formas de desenvolvimento das forças produtivas estas re- 
lações se transformam em seus grilhões. Sobrevém então uma época de revolução social. Com a transformação da base econômica, toda a enorme superestrutura se transtorna com maior ou menor rapidez" (Marx, 1974:135-136).

9. Na última nota do capítulo "Organização Social”, Prado Jr. observa que já teria discutido, de forma resumida, a mesma questão em Evolução Política do Brasil. Ver FBC:297.

10. Como observa Prado Jr. ao falar do aumento da massa inorgânica da população final do século XVIII, "em nenhuma época e lugar isto se torna mais catastrófico e atinge mais profundamente a colônia, que no momento preciso em que abordamos a nossa história, e nos distritos da mineração" (FBC:286).

11. Essa oscilação entre analítico e normativo foi assinalada por Ricupero (2000:133). Para ele, no entanto, o aspecto analítico da abordagem de Caio Prado Jr. estaria associado à noção de colônia; o normativo, ao tema da nação. Como os dois conceitos estão reciprocamente definidos, parece-me melhor afirmar que ambos contêm em si tanto um aspecto normativo quanto uma dimensão analítica. 


\section{REFERÊNCIAS BIBLIOGRÁFICAS}

ARENDT, Hannah. (1979), “O Conceito de História: Antigo e Moderno”, in Entre o Passado e o Futuro (2a ed.). São Paulo, Perspectiva.

COUTINHO, Carlos Nelson. (1989), “Uma Via 'Não Clássica' para o Capitalismo”, in M. A. D’Incao (org.), História e Ideal: Ensaios sobre Caio Prado Jr. São Paulo, Brasiliense/Unesp.

DIAS, Maria Odila Leite da Silva. (1989), "Impasses do Inorgânico", in M. A. D’Incao (org.), História e Ideal: Ensaios sobre Caio Prado Jr. São Paulo, Brasiliense/Unesp, pp. 377-405.

KOSELLECK, Reinhart. (1985), Futures Past: On the Semantics of Historical Time. Cambridge, The MIT Press.

MARCUSE, Herbert. (1978), Razão e Revolução (3a ed.). Rio de Janeiro, Paz e Terra.

MARX, Karl. (1974), "Para a Crítica da Economia Política", in Manuscritos Econômico-Filosóficos e Outros Textos Escolhidos. São Paulo, Abril Cultural.

PRADO JR., Caio. (1983) [1933], Evolução Política do Brasil. São Paulo, Brasiliense. . (1987) [1942], Formação do Brasil Contemporâneo: Colônia. São Paulo, Brasiliense. . (s.d.) [1945], História Econômica do Brasil. São Paulo, Círculo do Livro. . (1987) [1966], A Revolução Brasileira. São Paulo, Brasiliense.

RICUPERO, Bernardo. (2000), Caio Prado Jr. e a Nacionalização do Marxismo no Brasil. São Paulo, Departamento de Ciência Política da Universidade de São Paulo/Editora 34/Fapesp. 


\begin{abstract}
"The Colonial Background of Modern Brazil". "Revolution of Independence", and History of Brazil in Caio Prado Jr.
\end{abstract}

This article aims to analyze key aspects of Brazil's historical formation as elaborated by Caio Prado Jr. in his main works on Brazilian history, Evolução Politica do Brasil (1933), The Colonial Background of Modern Brazil (published in Portuguese in 1942; first English edition in 1967), and História Econômica do Brasil (1945). The author analyzes how Caio Prado Jr. engages in a dialogue with Marxist thought in his approach to the "revolution of independence" as a watershed in the historical development of Brazilian society.

Key words: Caio Prado Jr.; Brazilian history; nation

\title{
RÉSUMÉ
}

"Du Brésil Colonie d'Hier au Brésil Nation de Demain". "Révolution de l'Indépendance" et Histoire du Brésil chez Caio Prado Jr.

Dans cet article, on examine certains aspects de l'image du processus de formation historique du Brésil, que Caio Prado Jr. élabore dans ses principaux travaux consacrés à l'histoire du pays: Évolution Politique du Brésil [Evolução Política do Brasil] (1933), Formation du Brésil Contemporain: Colonie [Formação do Brasil Contemporâneo: Colônia] (1942) et Histoire Économique du Brésil [História Econômica do Brasil] (1945). Ainsi, on cherche à relier le dialogue de Caio Prado Jr., penseur marxiste, à son approche de la "révolution de l'indépendance", une ligne de division dans le développement historique de la société brésilienne.

Mots-clé: Caio Prado Jr.; histoire du Brésil; nation 